\title{
Outbreak of coronavirus in Iran compared to countries with the highest incidence
}

\author{
Elham Nazari1 ${ }^{1}$ (D) Hamed Tabesh ${ }^{1 *(D)}$ \\ ${ }^{1}$ Department of Medical Informatics, Faculty of Medicine, Mashhad University of Medical Sciences, Mashhad, Iran
}

\begin{tabular}{ll}
\hline Article Info & A B S T R A C T \\
\hline $\begin{array}{l}\text { Article type: } \\
\text { Research }\end{array}$ & $\begin{array}{l}\text { Introduction: The coronavirus outbreak has become a serious issue of the } \\
\text { entire world. In some ways, the ability to provide outbreak rate prediction }\end{array}$ \\
& $\begin{array}{l}\text { is helpful. Therefore the main purpose of this study is to investigate the } \\
\text { Article History: }\end{array}$ \\
$\begin{array}{l}\text { Received: } 2020-07-06 \\
\text { incidence pattern of Confirmed COVID-19 Cases in Iran, and comparison }\end{array}$ \\
between countries with high infected person such as USA, Brazil and others.
\end{tabular}

Published: 2020-08-03

\section{* Corresponding author: \\ Hamed Tabesh}

Department of Medical Informatics, Faculty of Medicine, Mashhad University of Medical Sciences, Mashhad, Iran

Email: Tabeshh@mums.ac.ir

Keywords:
Coronavirus
Epidemiology
Outbreak
COVID-19

Keywords:

Epidemiolog

Outbreak

COVID-19
Material and Methods: A total of 7801401 infected cases with COVID 19 related countries with highest infection, USA, Brazil, India, Russia, Peru, Chile, Mexico, Spain, UK, South Africa, Iran and Pakistan in 17 weeks timespan was extracted from the Daily New Cases chart at https://www.worldmeters. Info/coronavirus/. Also, the incidence rate pattern was presented. The frequency distribution charts used to compare countries.

Results: In Iran, from the interval of first week to the end of fifth week after observing the 100th case of infection, the trend of identifying patients was upward, and after that, it showed a decreasing tendency until the end of the 10th week. However, it seems that from the 10th to the 12th week, the trend has been increasing and after that it has been almost constant. In countries such as South Africa, India, and Brazil, however, this trend has roughly always been ascending during this period, and in other countries it has been fluctuated.

Conclusion: The Covid-19 has become pandemic disease. Finding similar incidence rate with other countries aimed for applying appropriate intervention is helpful.

Cite this paper as:

Nazari E, Tabesh H. Outbreak of Coronavirus in Iran Compared to Countries with the Highest Incidence. Front Health Inform. 2020; 9: 38. DOI: $\underline{10.30699 / f h i . v 9 i 1.228}$

\section{INTRODUCTION}

According to the World Health Organization (WHO), the coronavirus outbreak has become a serious issue of the entire world [1]. This virus has infected more than 200 countries and 15,000,000 people and killed 600,000 people so far [2]. The virus has infected all industries, especially healthcare industry and has imposed higher costs for everyone $[\underline{3}, \underline{4}]$. Coronavirus is increasing in various countries regardless of race, climate and other factors []ㅡ. Since there is currently no cure for the virus, the only solution is to use appropriate prevention strategies. The unpredicted prevalence rate is another problem in reducing transmission []. There are many countries that don't have well-developed health care systems, knowledge of the prevalence rate in these countries is very useful. The only information available about the prevalence rate is the use of the prevalence rate in countries with high rates of infection, such as China, which have been infected earlier. By comparing the prevalence rate with high rate countries and finding similarities, their interventions can be used to reduce the outbreak. This provides more time for a treatment to be developed also helps resource management $[\underline{7}, \underline{8}]$. Therefore the main purpose of this study was to investigate the incidence pattern of confirmed COVID-19 cases in Iran, and compare with countries with high infected person such as USA and Brazil for finding similarity incidence rate.

\section{MATERIAL AND METHODS}

According to the report on July 20, 2020 in world meters info page (https://www.worldometers. Info/coronavirus/) more than 15 million infected cases with CVID-19 have been identified worldwide. The epidemics in USA, Brazil, India, Russia, Peru, Chile, Mexico, Spain, UK, South Africa, Iran and Pakistan have been the highest, respectively. In this study, the total number of cases per day and per country were extracted based on the Daily New Cases 
chart and stored in Excel 2016 worksheets (7801401 cases). Also the study period considered 17 weeks since the hundred infected cases has observed for each country. In this study, day 1 indicate 100 or more COVID-19 infected case had been identified in that country. For Iran Feb 26, USA and Spain, Mar 2, UK, Mar 5,Brazil Mar 13, India Mar 14,Chile and Pakistan Mar 16, Russia Mar 17,South Africa Mar 18 and Mexico Mar 19 was considered as first day. The number of USA patients recorded from Mar 2 to June29, number of Brazil cases from Mar 13 to Jul11, number of India from March 14 to Jul 12, number of Russia from Mar 17 to Jul 15, number of Peru from Mar 17 to Jul 15, number of Chile from Mar 16 to Jul 14, number of Mexico from Mar 19 to Jul 17 , number of infected Spain from Mar 2 to June 29 , number of infected UK from Mar 5 to Jul 2, number of infected South Africa from Mar 18 to Jul 16, number of infected Iran from Feb 26 to June 23 and number of infected Pakistan from Mar 16 to Jul 14 imported to study. The main purpose is to discover incidence rate patterns in the countries with high infection rates. To achieve this, draw a frequency distribution chart and compare with target countries

\section{RESULTS}

Analytical information about the study is observed in Table1 and Fig 1.

In all countries, in the $1^{\text {st }}$ five weeks after observing the $100^{\text {th }}$ case of the disease, an upward trend is seen in the number of patients. Probably either no intervention has taken place or the effect of the intervention is not seen. In the $1^{\text {st }}$ ten weeks after the $1^{\text {st }}$ case of the disease, the number of patients in the United States, Russia, the United Kingdom, and Iran decreased such that in the $7^{\text {th }}$ week in the United States, in the $9^{\text {th }}$ week in Russia, in the $8^{\text {th }}$ week in the $\mathrm{UK}$, and in the $6^{\text {th }}$ week in Iran the trend decreased compared to previous weeks. While in countries such as Brazil, India, Peru, Chile, Mexico, and South Africa the number of patients was constantly increasing during this period.

Table 1: Frequency for coronavirus outbreak during 17 weeks since the hundred cases has observed.

\begin{tabular}{|c|c|c|c|c|c|c|c|c|c|c|c|c|}
\hline $\begin{array}{l}\sum_{\mathbb{D}} \\
\frac{D}{\lambda}\end{array}$ & 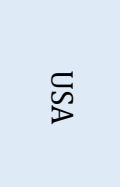 & 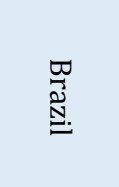 & 胥 & 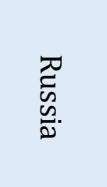 & $\begin{array}{l}\vec{D} \\
\vec{Z}\end{array}$ & $\stackrel{2}{\stackrel{0}{0}}$ & $\begin{array}{l}3 \\
\frac{3}{x} \\
\frac{x}{0}\end{array}$ & $\begin{array}{l}\tilde{D} \\
\text { O. }\end{array}$ & $\stackrel{\complement}{\pi}$ & 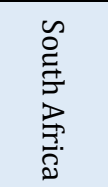 & 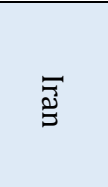 & 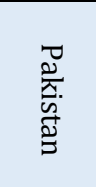 \\
\hline 1 & 441 & 489 & 149 & 324 & 278 & 558 & 287 & 554 & 311 & 438 & 2197 & 592 \\
\hline 2 & 2918 & 2015 & 555 & 341 & 534 & 1630 & 740 & 6757 & 1840 & 644 & 5120 & 722 \\
\hline 3 & 29335 & 4627 & 2072 & 4006 & 1496 & 2367 & 1407 & 18826 & 5656 & 369 & 7169 & 1440 \\
\hline 4 & 101201 & 8951 & 4012 & 10831 & 6830 & 2807 & 2218 & 44974 & 16094 & 570 & 7450 & 1464 \\
\hline 5 & 176523 & 10894 & 5906 & 26019 & 6022 & 3000 & 3654 & 43687 & 24403 & 959 & 17588 & 2852 \\
\hline 6 & 193263 & 15810 & 8082 & 34384 & 10862 & 3305 & 6208 & 30156 & 30165 & 1361 & 14996 & 4436 \\
\hline 7 & 176146 & 32385 & 10974 & 51710 & 16182 & 6847 & 8626 & 28575 & 27464 & 2222 & 10291 & 6169 \\
\hline 8 & 189850 & 43584 & 19996 & 65974 & 17633 & 9624 & 10690 & 26419 & 20837 & 6658 & 8413 & 9393 \\
\hline 9 & 178636 & 57026 & 22976 & 58435 & 22874 & 16054 & 14160 & 17700 & 26892 & 5126 & 6588 & 9210 \\
\hline 10 & 156475 & 92698 & 34146 & 53486 & 24496 & 26968 & 17966 & 16362 & 22910 & 6261 & 6313 & 12476 \\
\hline 11 & 145666 & 107922 & 42068 & 52536 & 40288 & 30067 & 19303 & 9576 & 17266 & 9875 & 9117 & 13147 \\
\hline 12 & 138842 & 147532 & 54357 & 52917 & 24812 & 33931 & 88808 & 4664 & 13455 & 15466 & 11878 & 26483 \\
\hline 13 & 133454 & 159643 & 62981 & 51957 & 29256 & 41486 & 25679 & 4029 & 9706 & 20913 & 12562 & 35559 \\
\hline 14 & 288950 & 153457 & 74186 & 46822 & 20291 & 32349 & 68383 & 1912 & 8388 & 25696 & 15971 & 32139 \\
\hline 15 & 136691 & 194579 & 97719 & 41451 & 21555 & 25019 & 29242 & 2211 & 7220 & 39413 & 15231 & 21867 \\
\hline 16 & 172986 & 221299 & 120312 & 33402 & 17505 & 19533 & 36238 & 2163 & 6286 & 56522 & 14501 & 21962 \\
\hline 17 & 246263 & 215762 & 148699 & 39300 & 20623 & 16484 & 36483 & 2266 & 5232 & 73627 & 14919 & 17054 \\
\hline
\end{tabular}



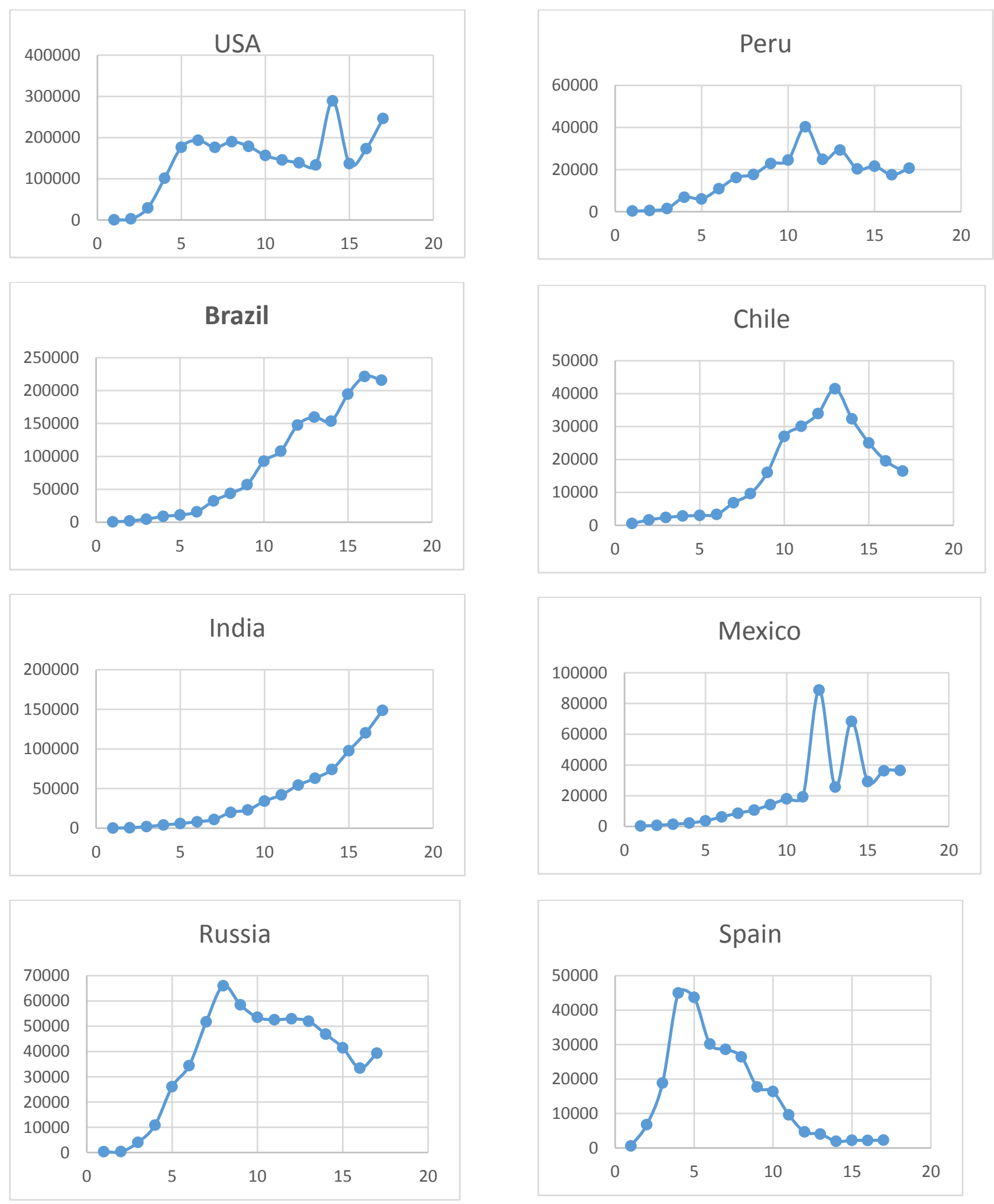

Fig 1: Frequency for coronavirus outbreak in USA, Brazil, India, Russia, Peru, Chile, Mexico and Spain during 17 weeks since the hundred cases has observed 

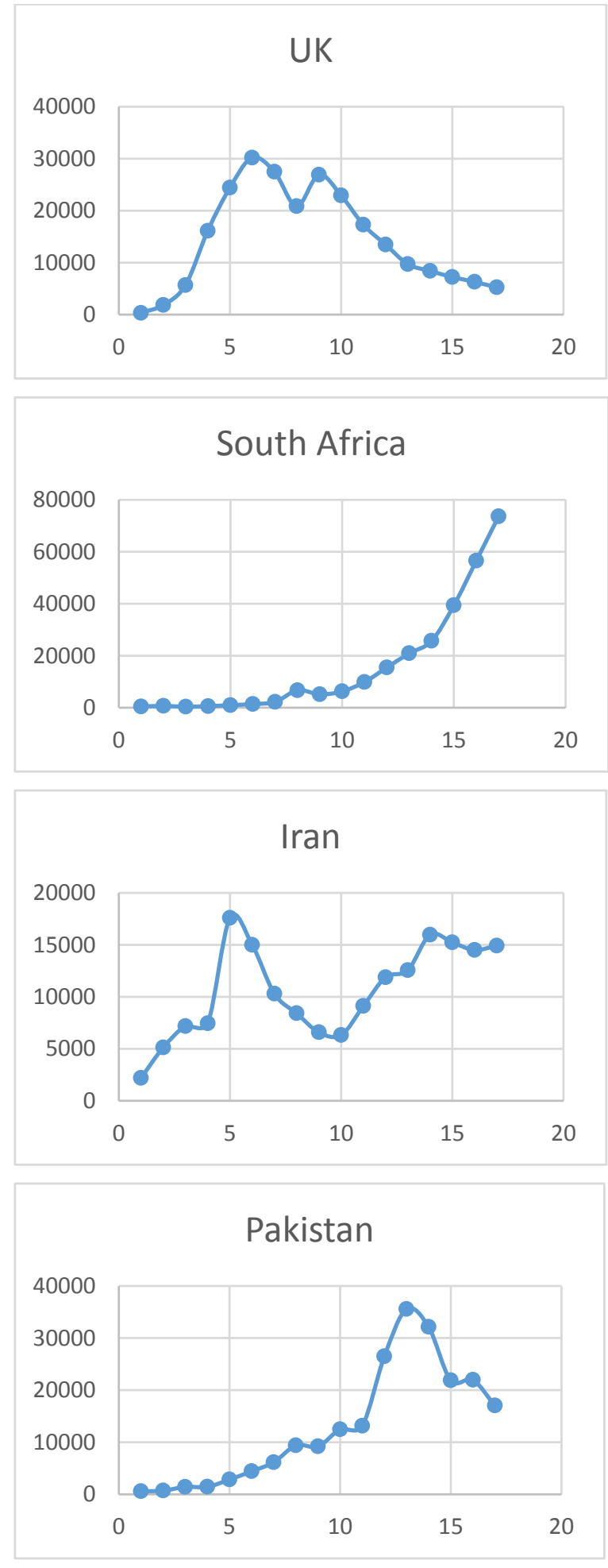

Fig 1 (Continue): Frequency for coronavirus outbreak in UK, South Africa, Iran and Pakistan during 17 weeks since the hundred cases has observed.

Between the $10^{\text {th }}$ and $15^{\text {th }}$ weeks after observing the $100^{\text {th }}$ person with Covid-19, there was an approximately declining trend in India, Russia, Spain, and the United Kingdom, a nearly upward trend was observed in Brazil, South Africa, and Iran, and in other countries the tendency was oscillating.

\section{DISCUSSION}

The Coronaviruses (CoVs) have substantially caused a great concern in the century and rapidly spread throughout the world. The outbreak of coronavirus has resulted in applying useful approach for prevention. Therefore the main purpose of this study was to investigate the incidence pattern of confirmed COVID-19 Cases in Iran, and comparison between countries with high infected person such as USA, Brazil, India, Russia, Peru and others. Findings show in Iran, from week one to the end of week five the trend of identifying patients was increasing, and after that, it showed a decreasing trend until the end of the 10th week. However, it seems that from the 10 th to the 12 th week, the trend has been increasing and after that it has been almost constant. In countries such as South Africa, India, and Brazil, however, this trend has roughly always been upward during this period, and in other countries it has been fluctuated. Countries with a declining incidence of Covid-19 appear to have used beneficial interventions and methods that were effective in reducing the spread of the disease.

\section{CONCLUSION}

It is recommended that other countries, being informed of those interventions, use appropriate strategies to prevent further spread of the disease. Countries can be prepared to face an unpredictable disaster, knowing the incidence rate. Also, the prevention and prediction strategies such as information about the same incidence rate of other countries aimed at applying appropriate intervention is a necessity.

\section{AUTHOR'S CONTRIBUTION}

The authors agree on this final form of the manuscript, and attested that all authors contributed in the final draft of the manuscript.

\section{CONFLICTS OF INTEREST}

The authors declare no conflicts of interest regarding the publication of this study.

\section{FINANCIAL DISCLOSURE}

No financial interests related to the material of this manuscript have been declared. 
2. COVID-19 coronavirus pandemic [Internet]. 2020 [cited: 12 Mar 2020; updated: 04 Aug 2020]. Available from: https://www.worldometers.info/coronavirus/

3. The impact of coronavirus across industry and finance [Internet]. 2020 [cited: 12 Mar 2020; updated: 27 Jan 2020]. Available from: https://www.ft.com/content/f3fcdc5a-4119-11eabdb5-169ba7be433d

4. Organisation for Economic Co-operation and Development. Coronavirus: The world economy at risk [Internet]. 2020 [cited: 2 Mar 2020]. Available from:

http://www.oecd.org/berlin/publikationen/InterimEconomic-Assessment-2-March-2020.pdf

5. COVID-19: Guidance for health professionals [Internet]. 2020 [cited: 1 Jul 2020; updated: 2 Jun 2020]. https://www.gov.uk/government/collections/wuha n-novel-coronavirus

6. Li G, De Clercq E. Therapeutic options for the 2019 novel coronavirus (2019-nCoV). Nat Rev Drug Discov. 2020; 19(3): 149-50. PMID: 32127666 DOI: 10.1038/d41573-020-00016-0 [PubMed]

7. Anderson RM, Heesterbeek H, Klinkenberg D, Hollingsworth TD. How will country-based mitigation measures influence the course of the COVID-19 epidemic? The Lancet. 2020; 395: 931-4.

8. Bowman S, Unwin N, Critchley J, Capewell S, Husseini A, Maziak W, et al. Use of evidence to support healthy public policy: A policy effectiveness-feasibility loop. Bull World Health Organ. 2012; 90(11): 847-53. PMID: 23226897 DOI: 10.2471/BLT.12.104968 [PubMed] 